\title{
Changing practice patterns of Gamma Knife versus linear accelerator-based stereotactic radiosurgery for brain metastases in the US
}

\author{
Henry S. Park, MD, MPH, ${ }^{1}$ Elyn H. Wang, BA, ${ }^{1}$ Charles E. Rutter, MD, ${ }^{1}$ \\ Christopher D. Corso, MD, PhD, ${ }^{1}$ Veronica L. Chiang, MD, ${ }^{1,2}$ and James B. Yu, MD, MHS ${ }^{1}$ \\ Departments of ${ }^{1}$ Therapeutic Radiology and ${ }^{2}$ Neurosurgery, Yale University School of Medicine, New Haven, Connecticut
}

OBJECTIVE Single-fraction stereotactic radiosurgery (SRS) is a crucial component in the management of limited brain metastases from non-small cell lung cancer (NSCLC). Intracranial SRS has traditionally been delivered using a framebased Gamma Knife (GK) platform, but stereotactic modifications to the linear accelerator (LINAC) have made an alternative approach possible. In the absence of definitive prospective trials comparing the efficacy and toxicities of treatment between the 2 techniques, nonclinical factors (such as technology accessibility, costs, and efficiency) may play a larger role in determining which radiosurgery system a facility may choose to install. To the authors' knowledge, this study is the first to investigate national patterns of GK SRS versus LINAC SRS use and to determine which factors may be associated with the adoption of these radiosurgery systems.

METHODS The National Cancer Data Base was used to identify patients $>18$ years old with NSCLC who were treated with single-fraction SRS to the brain between 2003 and 2011. Patients who received "SRS not otherwise specified" or who did not receive a radiotherapy dose within the range of 12-24 Gy were excluded to reduce the potential for misclassification. The chi-square test, t-test, and multivariable logistic regression analysis were used to compare potential demographic, clinicopathologic, and health care system predictors of GK versus LINAC SRS use, when appropriate.

RESULTS This study included 1780 patients, among whom 1371 (77.0\%) received GK SRS and 409 (23.0\%) underwent LINAC SRS. Over time, the proportion of patients undergoing LINAC SRS steadily increased, from $3.2 \%$ in 2003 to $30.8 \%$ in $2011(p<0.001)$. LINAC SRS was adopted more rapidly by community versus academic facilities (overall $29.2 \%$ vs $17.2 \%, p<0.001$ ). On multivariable analysis, 4 independent predictors of increased LINAC SRS use emerged, including year of diagnosis in 2008-2011 versus 2003-2007 (adjusted OR [AOR] 2.04, 95\% Cl 1.52-2.73, $p<0.001$ ), community versus academic facility type (AOR $2.04,95 \% \mathrm{Cl} 1.60-2.60, p<0.001$ ), non-West versus West geographic location (AOR 4.50, 95\% $\mathrm{Cl} 2.87-7.09, p<0.001$ ), and distance from cancer reporting facility of $<20$ versus $\geq 20$ miles (AOR 1.57, 95\% Cl 1.21-2.04, $p=0.001$ ).

CONCLUSIONS GK remains the most commonly used single-fraction SRS modality for NSCLC brain metastases in the US. However, LINAC-based SRS has been rapidly disseminating in the past decade, especially in the community setting. Wide geographic variation persists in the distribution of GK and LINAC SRS cases. Further comparative effectiveness research will be needed to evaluate the impact of these shifts on SRS-related toxicities, local control, and survival, as well as treatment costs and efficiency.

http://thejns.org/doi/abs/10.3171/2015.4.JNS1573

KEY WORDS Gamma Knife; linear accelerator; patterns of care; brain metastases; oncology; stereotactic radiosurgery

$\mathrm{S}$ TEREOTACTIC radiosurgery (SRS) has become highly desirable as first-line or salvage treatment for patients with limited brain metastases from non-small cell lung cancer (NSCLC) due to minimization of treatment-related morbidity. The addition of single-dose SRS to whole-brain radiotherapy improves local tumor control and maintenance of performance status for these patients, with a potential overall survival benefit in patients with a single metastasis. ${ }^{4,10}$ In facilities where sensitive serial surveillance imaging with MRI and effective salvage therapies for intracranial failures are available, SRS without upfront whole-brain radiotherapy is increasingly being

ABBREVIATIONS AOR = adjusted odds ratio; GK = Gamma Knife; LINAC = linear accelerator; NCDB = National Cancer Data Base; NSCLC = non-small cell lung cancer; RTOG = Radiation Therapy Oncology Group; SRS = stereotactic radiosurgery.

SUBMITTED January 20, 2015. ACCEPTED April 14, 2015.

INCLUDE WHEN CITING Published online October 16, 2015; DOI: 10.3171/2015.4.JNS1573. 
considered a reasonable approach. Three recent Phase III studies have demonstrated noninferior survival and neurocognitive outcomes. . $, 6,7,9^{-1}$

Intracranial SRS was initially made feasible using the Gamma Knife (GK) platform, which was developed by Lars Leksell in $1951 .{ }^{11}$ GK-based radiosurgery uses multiple Cobalt-60 sources arranged hemispherically around a single isocenter to treat tumors from at least 192 angles simultaneously and deliver highly conformal dose distributions. Stereotaxis is achieved with a fixed alignment of the patient to a physical coordinate system via a specialized stereotactic head frame. In contrast, linear accelerator (LINAC)-based radiosurgery was developed as an alternative to GK SRS in the 1980s, using a standard LINAC modified for stereotactic purposes. ${ }^{8}$ This technique uses a collimated x-ray beam focused on an intracranial target, around which the LINAC gantry and couch can rotate to produce multiple noncoplanar intersecting arcs of radiation..$^{15}$ Following improvements in these modifications and treatment planning systems, LINAC SRS was marketed as having acceptably similar precision, accuracy, and mechanical stability. ${ }^{3}$ However, comparisons of efficacy between the 2 radiosurgery systems have been rarely performed, despite significant changes in reimbursement recently in the US. ${ }^{1}$

In the absence of definitive prospective trials comparing the efficacy and toxicities of treatment between the 2 techniques, nonclinical factors (such as technology accessibility, costs, and efficiency) may play a larger role in determining which radiosurgery system a facility may choose to install. The choice of radiosurgery platform, however, can have both short- and long-term consequences for local control, toxicities, and costs, which are yet unknown for patients and the health care system. Our study therefore aims to evaluate shifts in GK versus LINAC SRS use in the treatment of brain metastases in the US over the past decade, and to determine which factors may be associated with the adoption of these radiosurgery systems.

\section{Methods}

\section{Data Source and Study Population}

We performed a retrospective analysis of US national practice using the National Cancer Data Base (NCDB). The NCDB is a joint project of the Commission on Cancer of the American College of Surgeons and the American Cancer Society. It contains de-identified information from approximately $70 \%$ of newly diagnosed cancers in the US. The NCDB contains information that is unavailable in the Surveillance, Epidemiology, and End Results (SEER) database, including treatment details pertaining to radiotherapy dose, technique, and target. The data used in this study are derived from a de-identified NCDB file. The American College of Surgeons and the Commission on Cancer have not verified and are neither responsible for the analytical or statistical methodology used, nor the conclusions drawn from these data by the investigators.

The NCDB was used to identify patients $>18$ years old with NSCLC who were treated with single-fraction SRS to the brain between 2003 and 2011. Radiation treatment modality is explicitly coded in the NCDB, and patients who received "Gamma Knife SRS" or "linear acceleratorbased SRS" were included. Patients who received "SRS not otherwise specified" or who did not receive a radiotherapy dose within the range of 12-24 Gy were excluded to reduce the potential for misclassification due to miscoding during data submission to the NCDB.

\section{Statistical Methodology}

To assess temporal trends, SRS modality use was compared by year of diagnosis using chi-square tests. The distribution of categorical demographic, clinicopathologic, and health care system details was compared between GK and LINAC SRS patients using chi-square tests. Patient demographic variables included age, sex, race, median household income, education quartile by county of residence, and county population. Clinicopathologic details included tumor histology, Charlson/Deyo comorbidity score, and radiotherapy dose. Finally, health care system details included the academic affiliation of the reporting cancer center, geographic location, insurance type, and the linear distance from the patient's residence to the reporting facility. Because the distance from the patient's residence to the radiation treatment facility was not specifically recorded in the NCDB, we used distance to the cancer reporting facility as a surrogate for distance traveled to receive radiotherapy. To check the validity of this assumption, a sensitivity analysis of the impact of linear distance traveled was performed when including only the subset of patients for whom the reporting facility and treating facility were the same.

Multivariable logistic regression modeling using a backward conditional stepwise technique was used to adjust for potential confounders in identifying predictors of GK versus LINAC SRS use. Clinically relevant factors associated with a $p$ value $<0.10$ in univariable analyses were included in multivariable analysis. All tests were 2-sided, and a $p$ value $<0.05$ was considered statistically significant. All analyses were performed using SPSS version 21 (IBM SPSS). Our institution's Human Investigations Committee determined that this study was exempt from review, given that it used existing and de-identified data.

\section{Results}

A total of 4867 patients with NSCLC who were treated with single-fraction intracranial SRS were identified. We excluded 1619 patients who received SRS "not otherwise specified," as well as an additional 1468 patients who were not treated with a single dose of 12-24 Gy, leaving 1780 patients in our final cohort (Fig. 1). Among these patients, $1371(77.0 \%)$ received GK SRS and 409 (23.0\%) underwent LINAC SRS. Complete patient characteristics are detailed in Table 1.

Over time, the proportion of patients undergoing LINAC SRS steadily increased from $3.2 \%$ in 2003 to $30.8 \%$ in 2011 (14.2\% in 2003-2007 vs $26.5 \%$ in $2008-2011$, p < 0.001) (Fig. 2). LINAC SRS was adopted more rapidly by community compared with academic facilities (overall $29.2 \%$ vs $17.2 \%$, p < 0.001 ) (Fig. 3) and by practices in nonWestern compared with Western states (31.2\% vs $8.3 \%$, p $<0.001)$. 
TABLE 1. Patient demographic, clinicopathologic, and health care system characteristics

\begin{tabular}{|c|c|}
\hline Characteristic & No. of Pts $(\%)$ \\
\hline \multicolumn{2}{|l|}{ Age, yrs } \\
\hline$<55$ & $384(21.6)$ \\
\hline $55-64$ & $533(29.9)$ \\
\hline $65-74$ & $533(29.9)$ \\
\hline$\geq 75$ & $330(18.5)$ \\
\hline \multicolumn{2}{|l|}{ Sex } \\
\hline Male & $862(48.4)$ \\
\hline Female & $918(51.6)$ \\
\hline \multicolumn{2}{|l|}{ Race } \\
\hline White & $1493(83.9)$ \\
\hline Black & $205(11.5)$ \\
\hline Other & $82(4.6)$ \\
\hline \multicolumn{2}{|l|}{ Median income quartile, \$ } \\
\hline$<30,000$ & $249(14.0)$ \\
\hline $30,000-34,999$ & $277(15.6)$ \\
\hline $35,000-45,999$ & $446(25.1)$ \\
\hline$\geq 46,000$ & $706(39.7)$ \\
\hline Unknown & $102(5.7)$ \\
\hline \multicolumn{2}{|l|}{ Education quartile, $\%{ }^{*}$} \\
\hline$\geq 29$ & $258(14.5)$ \\
\hline $20-28.9$ & $365(20.5)$ \\
\hline $14-19.9$ & $401(22.5)$ \\
\hline$<14$ & $654(36.7)$ \\
\hline Unknown & $102(5.7)$ \\
\hline \multicolumn{2}{|l|}{ County population } \\
\hline Metropolitan, $>250,000$ population & $1265(71.1)$ \\
\hline Other & $402(22.6)$ \\
\hline Unknown & $113(6.3)$ \\
\hline \multicolumn{2}{|l|}{ Primary tumor histology } \\
\hline Adenocarcinoma & $1044(58.7)$ \\
\hline Squamous cell carcinoma & $242(13.6)$ \\
\hline Large cell carcinoma & $58(3.3)$ \\
\hline Other & $436(24.5)$ \\
\hline \multicolumn{2}{|l|}{ Charlson/Deyo score } \\
\hline 0 & $1274(71.6)$ \\
\hline 1 & $360(20.2)$ \\
\hline$\geq 2$ & $146(8.2)$ \\
\hline \multicolumn{2}{|l|}{ SRS modality } \\
\hline GK & $1371(77.0)$ \\
\hline LINAC & $409(23.0)$ \\
\hline \multicolumn{2}{|l|}{ Radiotherapy dose, Gy } \\
\hline $12-17$ & $368(20.7)$ \\
\hline $18-19$ & $468(26.3)$ \\
\hline $20-21$ & $597(33.5)$ \\
\hline $22-24$ & $347(19.5)$ \\
\hline \multicolumn{2}{|l|}{ Facility academic status } \\
\hline Academic & $920(51.7)$ \\
\hline
\end{tabular}

TABLE 1. Patient demographic, clinicopathologic, and health care system characteristics (continued)

\begin{tabular}{|c|c|}
\hline Characteristic & No. of Pts $(\%)$ \\
\hline \multicolumn{2}{|l|}{ Facility academic status (continued) } \\
\hline Comprehensive community cancer & $805(45.2)$ \\
\hline Community cancer or other & $55(3.1)$ \\
\hline \multicolumn{2}{|l|}{ Facility location } \\
\hline Northeast & $466(26.2)$ \\
\hline South & $481(27.0)$ \\
\hline Midwest & $532(29.9)$ \\
\hline West & $301(16.9)$ \\
\hline \multicolumn{2}{|l|}{ Insurance type } \\
\hline Private & $757(42.5)$ \\
\hline Medicaid & $103(5.8)$ \\
\hline Medicare & $803(45.1)$ \\
\hline Not insured & $57(3.2)$ \\
\hline Other or unknown & $60(3.4)$ \\
\hline \multicolumn{2}{|l|}{ Distance from reporting facility, miles } \\
\hline$<10$ & $704(39.6)$ \\
\hline $10-19$ & $361(20.2)$ \\
\hline $20-49$ & $356(20.0)$ \\
\hline$\geq 50$ & $284(16.0)$ \\
\hline Unknown & $75(4.2)$ \\
\hline \multicolumn{2}{|l|}{ Yr of diagnosis } \\
\hline 2003 & $31(1.7)$ \\
\hline 2004 & $81(4.6)$ \\
\hline 2005 & $107(6.0)$ \\
\hline 2006 & $139(7.8)$ \\
\hline 2007 & $148(8.3)$ \\
\hline 2008 & $199(11.2)$ \\
\hline 2009 & $314(17.6)$ \\
\hline 2010 & $371(20.8)$ \\
\hline 2011 & $390(21.9)$ \\
\hline
\end{tabular}

Pts = patients.

* Education quartile = percentage of adults in patient's zip code who do not have a high school diploma.

Patient factors found to be associated with increased probability of treatment with LINAC SRS compared with GK SRS on univariable analysis included higher median household income of the patient's area of residence $(25.8 \%$ top quartile vs $20.5 \%$ other, $\mathrm{p}=0.011$ ), higher educational attainment of the patient's area of residence $(17.8 \%$ bottom quartile vs $23.6 \%$ other, $\mathrm{p}=0.043$ ), shorter distance between the patient's residence and the reporting facility (26.0\% distance $<20$ miles vs $17.0 \%$ distance $\geq 20$ miles, $\mathrm{p}<0.001)$, and lower single-fraction dosing $(20.6 \%$ dose $12-19$ Gy vs $25.1 \%$ dose $20-24 \mathrm{~Gy}, \mathrm{p}=0.024$ ) (Table 2). A sensitivity analysis of distance traveled was performed as described above for the subset of patients for whom the cancer reporting facility and radiation treatment facility were the same (82.3\% of the sample), yielding similar findings (data not shown). No statistically significant association was found between SRS modality and patient age, 


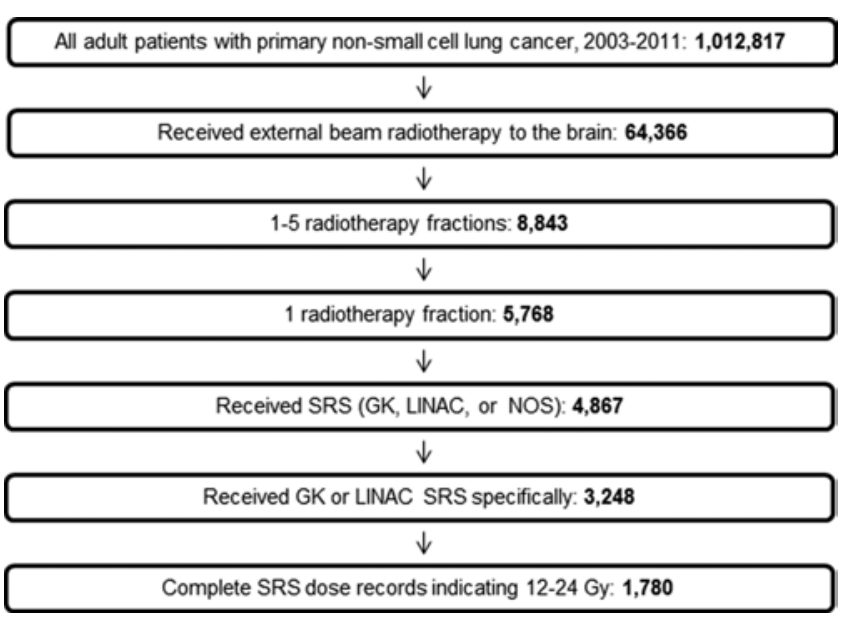

FIG. 1. Inclusion criteria for analysis. NOS = not otherwise specified.

sex, race, county population, tumor histology, CharlsonDeyo score, and insurance status.

On multivariable logistic regression analysis, 4 independent predictors of increased LINAC SRS use emerged. These included year of diagnosis between 2008 and 2011 versus 2003 and 2007 (adjusted OR [AOR] 2.04, 95\% CI $1.52-2.73, \mathrm{p}<0.001)$, community versus academic facility type (AOR $2.04,95 \%$ CI $1.60-2.60, \mathrm{p}<0.001$ ), nonWest geographic location (AOR 4.50, 95\% CI 2.87-7.09, $\mathrm{p}<0.001)$, and distance from cancer reporting facility of $<20$ versus $\geq 20$ miles (AOR 1.57, 95\% CI 1.21-2.04, $\mathrm{p}=$ 0.001) (Table 3).

\section{Discussion}

To our knowledge, the present study is the first to analyze national patterns of GK and LINAC-based SRS in the upfront management of NSCLC brain metastases. We found that most patients who receive single-fraction SRS for NSCLC brain metastases still undergo treatment with GK, but that the use of LINAC SRS has become much more common since 2003. Patients treated in facilities

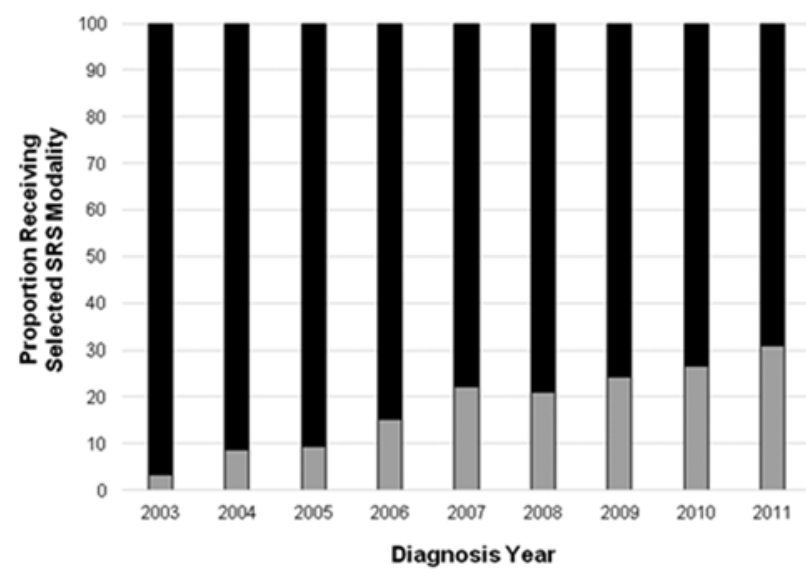

$\begin{array}{llllllllll}\text { - } G \text { K SRS } & 96.8 \% & 91.4 \% & 90.7 \% & 84.9 \% & 77.7 \% & 78.9 \% & 75.8 \% & 73.3 \% & 69.2 \%\end{array}$ $\begin{array}{llllllllll}\text { aLINAC SRS } & 3.2 \% & 8.6 \% & 9.3 \% & 15.1 \% & 22.3 \% & 21.1 \% & 24.2 \% & 26.7 \% & 30.8 \%\end{array}$

FIG. 2. Distribution of GK and LINAC-based SRS use by year of diagnosis.

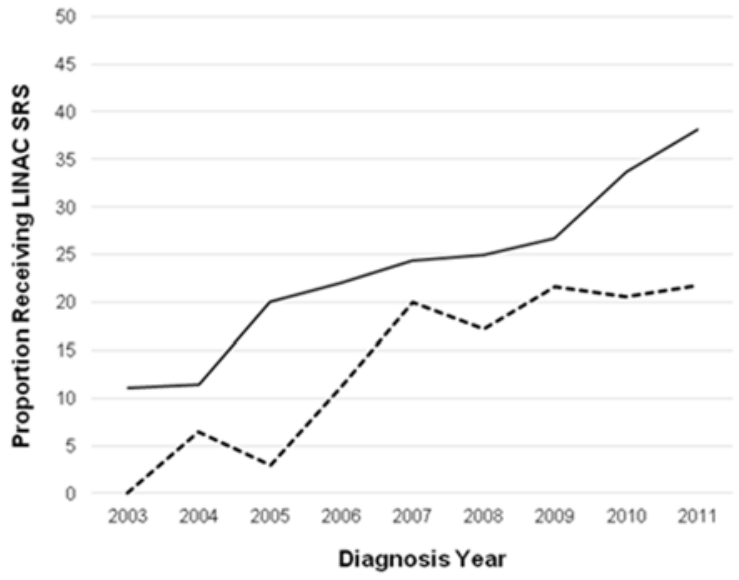

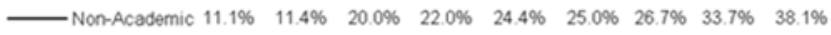

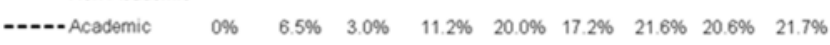

FIG. 3. Trends in LINAC-based SRS use by nonacademic versus academic facilities over time.

with a community compared with academic affiliation, located in non-Western compared with Western states, and located closer to the patient's residence are more likely to be treated with LINAC SRS compared with GK SRS.

The apparent increase in LINAC SRS use for this indication over time, especially in the community setting, may be attributable to several factors. One possible explanation may be that the relative ease of use and lower expenses associated with LINAC SRS compared with GK SRS may have led to an increased use of LINACs for SRS in the US. Cobalt-based dedicated intracranial radiosurgery machines are tightly regulated by the Nuclear Regulatory Commission, including the mandatory presence of a radiation oncologist for the entire procedure and the additional costs of regularly replacing the decaying cobalt sources. These restrictions may make GK installation more likely to be limited to large academic centers or large private referral hubs. ${ }^{3}$ In contrast, because LINAC-based SRS can be performed with an existing LINAC equipped with SRS modifications, can be used for nonintracranial targets, and does not mandate neurosurgical involvement, ${ }^{12}$ the purchase of an SRS-capable LINAC may be a more flexible and financially feasible option for smaller community facilities.

Another reason for these shifts may be related to changing referral patterns. If there is a growing perception among patients and providers that the 2 SRS approaches are equivalent, then they may feel increasingly comfortable with undergoing LINAC SRS closer to home rather than traveling farther for GK SRS. This hypothesis is supported by our finding that patients who live farther from their cancer reporting facility are less likely to undergo GK SRS. There may also be a knowledge gap regarding the well-documented technical differences between GK SRS and LINAC SRS. The dose fall-off for treatment of both single as well as multiple intracranial lesions using the GK Perfexion (Elekta) machine remains superior to any LINAC-based radiosurgery platform. ${ }^{13,14}$ In addition, there is a potential dosimetric advantage in terms of integral tumor dose for cobalt-based dedicated intracranial 
TABLE 2. Association of patient demographic, clinicopathologic, and health care system factors with selection of SRS modality

\begin{tabular}{|c|c|c|c|}
\hline \multirow[b]{2}{*}{ Characteristic } & \multicolumn{2}{|c|}{ No. of Pts (\%) } & \multirow[b]{2}{*}{$\begin{array}{c}\mathrm{p} \\
\text { Value }\end{array}$} \\
\hline & $\begin{array}{l}\text { GK SRS, } \\
n=1371\end{array}$ & $\begin{array}{c}\text { LINAC } \\
\text { SRS, } \\
n=409\end{array}$ & \\
\hline Age, yrs (Ref: $\geq 65$ yrs) & & & 0.128 \\
\hline$<55$ & $309(80.5)$ & $75(19.5)$ & \\
\hline $55-64$ & $411(77.1)$ & $122(22.9)$ & \\
\hline $65-74$ & $401(75.2)$ & $132(24.8)$ & \\
\hline$\geq 75$ & $250(18.2)$ & $80(24.2)$ & \\
\hline Sex & & & 0.736 \\
\hline Male & $667(77.4)$ & $195(22.6)$ & \\
\hline Female & $704(76.7)$ & $214(23.3)$ & \\
\hline Race (Ref: White) & & & 0.269 \\
\hline White & $1144(76.6)$ & $349(23.4)$ & \\
\hline Black & $160(78.0)$ & $45(22.0)$ & \\
\hline Other & $67(81.7)$ & $15(18.3)$ & \\
\hline $\begin{array}{l}\text { Median income quartile, } \$ \text { (Ref: } \\
\geq 46,000 \text { ) }\end{array}$ & & & 0.011 \\
\hline$<30,000$ & $206(82.7)$ & $43(17.3)$ & \\
\hline $30,000-34,999$ & $213(76.9)$ & $64(23.1)$ & \\
\hline $35,000-45,999$ & $354(79.4)$ & $92(20.6)$ & \\
\hline$\geq 46,000$ & $524(74.2)$ & $182(25.8)$ & \\
\hline Unknown & $74(72.5)$ & $28(27.5)$ & \\
\hline Education quartile, $\%$ (Ref: $\geq 29$ ) & & & 0.043 \\
\hline$\geq 29$ & $504(77.1)$ & $150(22.9)$ & \\
\hline $20-28.9$ & $309(77.1)$ & $92(22.9)$ & \\
\hline $14-19.9$ & $272(74.5)$ & $93(25.5)$ & \\
\hline$<14$ & $212(82.2)$ & $46(17.8)$ & \\
\hline Unknown & $74(72.5)$ & $28(27.5)$ & \\
\hline County population & & & 0.088 \\
\hline $\begin{array}{l}\text { Metropolitan, }>250,000 \text { popula- } \\
\text { tion }\end{array}$ & $964(76.2)$ & $301(23.8)$ & \\
\hline Other & $323(80.3)$ & $79(19.7)$ & \\
\hline Unknown & $84(74.3)$ & $29(25.7)$ & \\
\hline $\begin{array}{l}\text { Primary tumor histology (Ref: } \\
\text { adenocarcinoma) }\end{array}$ & & & 0.109 \\
\hline Adenocarcinoma & $790(75.7)$ & $254(24.3)$ & \\
\hline Squamous cell carcinoma & $181(74.8)$ & $61(25.2)$ & \\
\hline Large cell carcinoma & $40(69.0)$ & $18(31.0)$ & \\
\hline Other & $360(82.6)$ & $76(17.4)$ & \\
\hline Charlson/Deyo score (Ref: $\geq 2$ ) & & & 0.125 \\
\hline 0 & $993(77.9)$ & $281(22.1)$ & \\
\hline 1 & $273(75.8)$ & $87(24.2)$ & \\
\hline$\geq 2$ & $105(71.9)$ & $41(28.1)$ & \\
\hline Radiotherapy dose, Gy (Ref: <20) & & & 0.024 \\
\hline $12-17$ & $313(85.1)$ & $55(14.9)$ & \\
\hline $18-19$ & $351(75.0)$ & $117(25.0)$ & \\
\hline $20-21$ & $480(80.4)$ & $117(19.6)$ & \\
\hline $22-24$ & $227(65.4)$ & $120(34.6)$ & \\
\hline
\end{tabular}

TABLE 2. Association of patient demographic, clinicopathologic, and health care system factors with selection of SRS modality (continued)

\begin{tabular}{|c|c|c|c|}
\hline \multirow[b]{2}{*}{ Characteristic } & \multicolumn{2}{|c|}{ No. of Pts $(\%)$} & \multirow[b]{2}{*}{$\begin{array}{c}\mathrm{p} \\
\text { Value }\end{array}$} \\
\hline & $\begin{array}{l}\text { GK SRS, } \\
n=1371\end{array}$ & $\begin{array}{c}\text { LINAC } \\
\text { SRS, } \\
n=409\end{array}$ & \\
\hline $\begin{array}{l}\text { Facility academic status (Ref: } \\
\text { academic) }\end{array}$ & & & $<0.001$ \\
\hline Academic & $762(82.8)$ & $158(17.2)$ & \\
\hline $\begin{array}{l}\text { Comprehensive community } \\
\text { cancer }\end{array}$ & $573(71.2)$ & $232(28.8)$ & \\
\hline Community cancer or other & $36(65.5)$ & $19(34.5)$ & \\
\hline Facility location (Ref: West) & & & $<0.001$ \\
\hline Northeast & $355(76.2)$ & $111(23.8)$ & \\
\hline South & $374(77.8)$ & $107(22.2)$ & \\
\hline Midwest & $366(68.8)$ & $166(31.2)$ & \\
\hline West & $276(91.7)$ & $25(8.3)$ & \\
\hline Insurance type (Ref: private) & & & 0.390 \\
\hline Private & $590(77.9)$ & $167(22.1)$ & \\
\hline Medicaid & $85(82.5)$ & $18(17.5)$ & \\
\hline Medicare & $602(75.0)$ & $201(25.0)$ & \\
\hline Not insured & $46(80.7)$ & $11(19.3)$ & \\
\hline Other or unknown & $48(80.0)$ & $12(20.0)$ & \\
\hline $\begin{array}{l}\text { Distance from reporting facility, } \\
\text { miles (Ref: } \geq 20 \text { ) }\end{array}$ & & & $<0.001$ \\
\hline$<10$ & $531(75.4)$ & $173(24.6)$ & \\
\hline $10-19$ & $257(71.2)$ & $104(28.8)$ & \\
\hline $20-49$ & $285(80.1)$ & $71(19.9)$ & \\
\hline$\geq 50$ & $246(86.6)$ & $38(13.4)$ & \\
\hline Unknown & $52(69.3)$ & $23(30.7)$ & \\
\hline Year of diagnosis & & & $<0.001$ \\
\hline 2003-2007 & $434(85.8)$ & $72(14.2)$ & \\
\hline 2008-2011 & $937(73.5)$ & $337(26.5)$ & \\
\hline
\end{tabular}

Ref $=$ reference category for chi-square test when $\geq 2$ categories.

radiosurgery due to the greater inhomogeneity achieved. The limited comparative effectiveness data in the literature have been mixed. Initial prospective results from the Radiation Therapy Oncology Group (RTOG) 90-05 trial suggested a local control advantage to GK SRS. ${ }^{16}$ However, there were no significant survival differences between GK SRS and LINAC SRS in subgroup analysis of the more recent RTOG 95-08 study, although patients were not stratified by SRS modality prerandomization. ${ }^{4}$ It should be noted that even though GK SRS was previously reimbursed more than twice as much as LINAC SRS, Section 634 of the American Taxpayer Relief Act of 2012 equalized reimbursement between the 2 modalities. ${ }^{2}$ Whether this will further increase subsequent adoption of LINAC SRS will require more longitudinal study with updated data.

Limitations of this study include those inherent to retrospective analyses of large administrative databases. These include the possibilities of incomplete or biased data reporting and the potential of registrar miscoding 
TABLE 3. Multivariable logistic regression analysis of predictors of LINAC-based SRS use

\begin{tabular}{lllll}
\hline \multicolumn{1}{c}{ Characteristic } & \multicolumn{1}{c}{ Variables } & AOR & $95 \% \mathrm{Cl}$ & $\mathrm{p} \mathrm{Value}$ \\
\hline Yr of diagnosis & $2008-2011$ vs $2003-2007$ & 2.04 & $1.52-2.73$ & $<0.001$ \\
\hline Facility academic status & Nonacademic vs academic & 2.04 & $1.60-2.60$ & $<0.001$ \\
\hline Facility location & Non-West vs West & 4.50 & $2.87-7.09$ & $<0.001$ \\
\hline Distance from facility & $<20$ vs $\geq 20$ miles & 1.57 & $1.21-2.04$ & 0.001 \\
\hline
\end{tabular}

during data submission to the NCDB. In addition, there has been no verification that the data available through the NCDB is representative of the lung cancer patient population or the radiosurgery treatment population nationally. We attempted to account for possible miscoding by applying stringent inclusion criteria, which also significantly restricted our sample size and could further bias our findings. One example is our a priori decision to exclude the small minority of patients who received more than 1 fraction or a total dose outside the range of 12-24 Gy. Although LINAC SRS patients may be more likely to receive 2-5 fractions than GK SRS patients due to technical limitations, numerous other clinical variables (including lesion size) contribute to the decision to pursue fractionated rather than single-fraction radiosurgery, increasing the probability of confounded results. Although restricting our sample to those patients receiving a single fraction may slightly lower the absolute proportion of patients receiving LINAC SRS compared with GK SRS, we would not expect this restriction to bias our observed trends.

Several other details are not available in the database. Not only is there lack of differentiation among LINACbased modalities (i.e., CyberKnife [Accuray], Novalis TX [Varian and Brainlab], Trilogy [Varian], Synergy [Elekta], TomoTherapy [Accuray]), but key clinical information (such as number of brain metastases treated per single fraction session; volume of irradiated brain; treatment isodose lines; Karnofsky performance status; and outcome data regarding local control, distant intracranial control, extracranial control, and toxicities) were not available. Also, the NCDB only records the "dominant modality of radiation therapy used to deliver the most clinically significant regional dose to the primary volume of interest during the first course of treatment." Thus, patients who developed brain metastases after completion of definitive management of initially nonmetastatic NSCLC would not be captured, nor would those who received salvage SRS for intracranial recurrence after whole-brain radiation therapy. Subsequent SRS courses would also not be recorded. Although this limitation may decrease the generalizability of our results for patients with brain metastases, we would not expect that this would bias our comparison of SRS modalities significantly. Finally, because we do not have information regarding benign conditions such as vestibular schwannoma or trigeminal neuralgia, it is currently unknown whether we can extrapolate our findings to other SRS indications. Future research into practice pattern trends of GK SRS and LINAC SRS for nonmalignant diagnoses will help determine whether these observed shifts for brain metastases are more attributable to clinical or nonclinical factors.

\section{Conclusions}

GK remains the most commonly used machine for single-fraction SRS treatment of NSCLC brain metastases in the US. However, LINAC-based SRS has been rapidly disseminating in the past decade, especially in the community setting. Wide geographic variation persists in the distribution of GK and LINAC SRS cases. Not only is there a significant lack of SRS-specific training required in either neurosurgery or radiation oncology, the use of LINAC-based radiosurgery no longer mandates the input of a neurosurgeon and relies entirely on the radiation oncologist to account for neurological factors when delivering the treatment. ${ }^{12}$ Our data substantiate the need for further comparative effectiveness research to evaluate the impact of these shifts on SRS-related toxicities, local control, and survival, as well as treatment costs and efficiency. The forthcoming collaboration between the American Association of Neurological Surgeons (AANS) and the American Society for Radiation Oncology (ASTRO) to launch and support a national radiosurgery registry is expected to help achieve that goal. ${ }^{1}$

\section{Acknowledgment}

Dr. Yu receives research funding from 21 st Century Oncology and the PhRMA Foundation. These funding sources had no involvement in the design, analysis, or preparation of the manuscript.

\section{References}

1. American Society for Radiation Oncology: American Association of Neurological Surgeons (AANS) and American Society for Radiation Oncology (ASTRO) join forces to launch stereotactic radiosurgery (SRS) patient registry. ASTRO.org. September 14, 2014. (https://www.astro.org/News-and-Media/News-Releases/2014/AANS-and-ASTRO-join-forces-tolaunch-SRS-patient-registry.aspx) [Accessed August 6, 2015]

2. American Taxpayer Relief Act of 2012, Pub L No. 112-240, 126 Stat. 2313

3. Andrews DW, Bednarz G, Evans JJ, Downes B: A review of 3 current radiosurgery systems. Surg Neurol 66:559-564, 2006

4. Andrews DW, Scott CB, Sperduto PW, Flanders AE, Gaspar LE, Schell MC, et al: Whole brain radiation therapy with or without stereotactic radiosurgery boost for patients with one to three brain metastases: phase III results of the RTOG 9508 randomised trial. Lancet 363:1665-1672, 2004

5. Aoyama H, Shirato H, Tago M, Nakagawa K, Toyoda T, Hatano K, et al: Stereotactic radiosurgery plus whole-brain radiation therapy vs stereotactic radiosurgery alone for treatment of brain metastases: a randomized controlled trial. JAMA 295:2483-2491, 2006

6. Aoyama H, Tago M, Kato N, Toyoda T, Kenjyo M, Hirota 
S, et al: Neurocognitive function of patients with brain metastasis who received either whole brain radiotherapy plus stereotactic radiosurgery or radiosurgery alone. Int J Radiat Oncol Biol Phys 68:1388-1395, 2007

7. Chang EL, Wefel JS, Hess KR, Allen PK, Lang FF, Kornguth DG, et al: Neurocognition in patients with brain metastases treated with radiosurgery or radiosurgery plus whole-brain irradiation: a randomised controlled trial. Lancet Oncol 10:1037-1044, 2009

8. Deinsberger R, Tidstrand J: Linac radiosurgery as a tool in neurosurgery. Neurosurg Rev 28:79-91, 2005

9. Kocher M, Soffietti R, Abacioglu U, Villà S, Fauchon F, Baumert BG, et al: Adjuvant whole-brain radiotherapy versus observation after radiosurgery or surgical resection of one to three cerebral metastases: results of the EORTC 2295226001 study. J Clin Oncol 29:134-141, 2011

10. Kondziolka D, Patel A, Lunsford LD, Kassam A, Flickinger JC: Stereotactic radiosurgery plus whole brain radiotherapy versus radiotherapy alone for patients with multiple brain metastases. Int J Radiat Oncol Biol Phys 45:427-434, 1999

11. Leksell L: The stereotaxic method and radiosurgery of the brain. Acta Chir Scand 102:316-319, 1951

12. Lunsford LD, Chiang V, Adler JR, Sheehan J, Friedman W, Kondziolka D: A recommendation for training in stereotactic radiosurgery for US neurosurgery residents. J Neurosurg 117 Suppl:2-4, 2012

13. Ma L, Nichol A, Hossain S, Wang B, Petti P, Vellani R, et al: Variable dose interplay effects across radiosurgical apparatus in treating multiple brain metastases. Int J Comput Assist Radiol Surg [epub ahead of print], 2014

14. McDonald D, Schuler J, Takacs I, Peng J, Jenrette J, Vanek $\mathrm{K}$ : Comparison of radiation dose spillage from the Gamma
Knife Perfexion with that from volumetric modulated arc radiosurgery during treatment of multiple brain metastases in a single fraction. J Neurosurg 121 Suppl:51-59, 2014

15. Niranjan A, Maitz AH, Lunsford A, Gerszten PC, Flickinger JC, Kondziolka D, et al: Radiosurgery techniques and current devices. Prog Neurol Surg 20:50-67, 2007

16. Shaw E, Scott C, Souhami L, Dinapoli R, Bahary JP, Kline $\mathrm{R}$, et al: Radiosurgery for the treatment of previously irradiated recurrent primary brain tumors and brain metastases: initial report of radiation therapy oncology group protocol (90-05). Int J Radiat Oncol Biol Phys 34:647-654, 1996

\section{Disclosure}

The authors report no conflict of interest concerning the materials or methods used in this study or the findings specified in this paper.

\section{Author Contributions}

Conception and design: Park, Wang, Yu. Acquisition of data: Park. Analysis and interpretation of data: all authors. Drafting the article: Park, Wang. Critically revising the article: all authors. Reviewed submitted version of manuscript: all authors. Approved the final version of the manuscript on behalf of all authors: Park. Statistical analysis: Park. Study supervision: Chiang, Yu.

\section{Correspondence}

Henry S. Park, Department of Therapeutic Radiology, Yale University School of Medicine, Smilow Cancer Hospital, 35 Park St., LL 509, New Haven, CT 06519. email: henry.park@yale.edu. 